\title{
Review of research progress on soil moisture sensor technology
}

\author{
Limin $\mathrm{Yu}^{1,2}$, Wanlin Gao ${ }^{1}$, Redmond R. Shamshiri ${ }^{3}$, Sha Tao ${ }^{1 *}$, Yanzhao Ren ${ }^{1}$, \\ Yanjun Zhang ${ }^{2}$, Guilian $\mathrm{Su}^{2}$ \\ (1. College of Information and Electrical Engineering, China Agricultural University, Beijing 100083, China; \\ 2. College of Information Science and Engineering, Shandong Agriculture and Engineering University, Shandong 250100, China; \\ 3. Leibniz Institute for Agricultural Engineering and Bioeconomy, Potsdam-Bornim 14469, Germany)
}

\begin{abstract}
Soil moisture is directly related to the amount of irrigation in agriculture and influences the yield of crops. Accordingly, a soil moisture sensor is an important tool for measuring soil moisture content. In this study, the previous research conducted in recent 2-3 decades on soil moisture sensors was reviewed and the principles of commonly used soil moisture sensor and their various applications were summarized. Furthermore, the advantages, disadvantages, and influencing factors of various measurement methods employed were compared and analyzed. The improvements were presented by several scholars have established the major applications and performance levels of soil moisture sensors, thereby setting the course for future development. These studies indicated that soil moisture sensors in the future should be developed to achieve high-precision, low-cost, non-destructive, automated, and highly integrated systems. Also, it was indicated that future studies should involve the development of specialized sensors for different applications and scenarios. This review research aimed to provide a certain reference for application departments and scientific researchers in the process of selecting soil moisture sensor products and measuring soil moisture.
\end{abstract}

Keywords: soil moisture sensor, measurement principle, influencing factor, improvement method, development direction DOI: $10.25165 /$ j.ijabe.20211404.6404

Citation: Yu L M, Gao W L, Shamshiri R R, Tao S, Ren Y Z, Zhang Y J, et al. Review of research progress on soil moisture sensor technology. Int J Agric \& Biol Eng, 2021; 14(4): 32-42.

\section{Introduction}

Fresh water is a renewable but variable natural resource. Fresh water available for human consumption amounts to only $0.01 \%$ of the total water on the planet ${ }^{[1]}$. Owing to population growth and an increase in water consumption per person, several regions have already confronted water shortages. Agriculture is responsible for the largest consumption of fresh water in the world, accounting for up to $80 \%$ of the water demand of the society ${ }^{[2]}$. It is estimated that $70 \%$ of the water of the world is used for irrigation, and $15 \%-35 \%$ of the water withdrawn from irrigation is unsustainable ${ }^{[3]}$. Traditional field agriculture requires large quantities of water, and the possible inefficient use of water in field agriculture could trigger excess watering, leading to the leaching of nutrients and fertilizers in the root system and ultimately reducing crop yields.

As an important soil content, moisture does not only affects the

\section{Received date: 2021-01-04 Accepted date: 2021-04-29}

Biographies: Limin $\mathbf{Y u}, \mathrm{PhD}$ candidate, research interest: agricultural informationization and application, Email: 18615177887@163.com; Wanlin Gao, $\mathrm{PhD}$, Professor, research interest: agricultural informationization and application specific chip, Email: wanlin_cau@163.com; Redmond R. Shamshiri, $\mathrm{PhD}$, research interest: digital agriculture, LPWAN sensors, simulation and modeling, Email: RShamshiri@atb-potsdam.de; Yanzhao Ren, Post Doctorate, research interest: agricultural IoT, automatic operating equipment, and intelligent video projection equipment, Email: xiaozhaochina@163.com; Yanjun Zhang, Master, Associate Professor, research interest: computer application, Email: 94745611@qq.com; Guilian Su, Master, Associate Professor, research interest: image processing and information security, Email: wysgl@163.com.

*Corresponding author: Sha Tao, $\mathrm{PhD}$, Associate Professor, research interest: agricultural informationization and application. College of Information and Electrical Engineering, China Agricultural University, No.17, Qinghua East Road, Haidian District, Beijing 100083, China. Tel: +86-10-62738535, Email: taosha20070608@163.com. physical properties of the soil, but also restricts the dissolution and transfer of nutrients in the soil, including the activities of microorganisms. In addition, moisture determines soil fertility and sustains the survival of all plants. Basically, soil moisture refers to the water content in the soil, and crop growth is closely related to the soil moisture content. If the soil moisture is considerably high, then the root respiration of the crop will be affected. By contrast, when moisture is extremely low, the leakage of nutrients and fertilizers in the water will trigger groundwater pollution, limiting the absorption of the fertilizer by the crop and increasing soil salinization.

Proper water irrigation is realized via the monitoring of the soil moisture and accurate determination of the soil moisture content. Therefore, it is beneficial to study and understand the dynamic changes and spatial distribution of soil moisture as well as the different requirements of different crops for soil water content in the same period. Owing to the varying soil moisture content requirements in different periods and the influence of soil moisture content on crop yields, ensuring that the soil has an appropriate amount of moisture is an important factor to consider for protecting healthy crop growth ${ }^{[4]}$.

Soil moisture has been studied for decades. Dakochayev ${ }^{[5]}$ from Russia conducted location observations of soil moisture, which created a precedent for research on soil moisture. In 1943, Edferson and Anderson ${ }^{[5]}$ from the United States expanded the scope of soil moisture research based on thermodynamic observation; their studies of soil moisture and energy changes gave rise to new research avenues and test methods. Later, Philippe ${ }^{[5]}$ from Australia presented the problem of water transport in the "soil-plant-atmosphere continuum" based on the concept of soil water potential, thereby correlating the regulation of soil moisture with the status of the plant water environment. For the previous 
studies, this work opens up new fields and development directions for the large-scale monitoring of and research on dynamic changes in soil moisture and energy conversion ${ }^{[5]}$. Recently, Shamshiri et al. ${ }^{[6]}$ used capacitive sensors in berry orchards to test the soil moisture for IoT monitoring, in order to fully understand the changes of soil moisture during the growth of berries. Its use has proven effective in improving digital agricultural management.

The basic method for measuring soil moisture is the drying method, which is regarded as the most conventional and accurate method adopted for measuring the quality of other techniques. It can also be used as a standard for calibrating other methods, i.e., by oven drying the soil sample to a constant weight. At this point, the free water in the soil moisture is all lost in the form of steam and then weighed to obtain the soil moisture content ${ }^{[7]}$.

In recent years, owing to the development of science and technology, as well as the in-depth study on soil physics, several methods for soil moisture measurement have been developed. The real-time monitoring and spatiotemporal variability of soil moisture have become hot spots in the field of soil research ${ }^{[8]}$. Accordingly, this has led to the large-scale fabrication and applications of soil moisture sensors, which can swiftly and conveniently obtain soil moisture content. With the rapid development of modern sensor technology and the rise of the Internet of Things (IoTs) industry, the research and development of various sensors that can quickly obtain information on objects and surrounding environments have attracted considerable attention. Soil science and agricultural engineering experts have conducted several studies on sensors. One of the unique studies presented at the 19th International Soil Science Conference, held in 2010, was titled "Soil sensor: A rapid soil measuring technology".

Although several studies ${ }^{[6,7]}$ on soil sensors have already been performed, soil sensor users still encounter numerous challenges owing to varying principles, types, and production standards, as well as the different qualities of soil moisture sensors. Consequently, this study has surpassed the works of relevant studies since 2000. The studies were obtained and analyzed, combined with the history of soil sensor development, analysis of the principles, methods, and applications from different perspectives. Then, the development trend of soil moisture sensors was discussed, with the expectation that the application departments, users, and scientific researchers that adopt soil sensor products provide certain reference value in the process and promote further research on soil moisture sensors.

\section{Soil properties}

The classification of soil texture is based on the combination of mineral particles in the soil with several types of retrieval systems. The international classification system divides soil texture into four groups (sand, loam, clay-loam, and clay) and 13 levels.

Soil electrical properties refer to the physical and electrical properties of soil, which are different from its electrochemical properties, including the natural electric field (electric potential), resistance (conductivity), electroosmosis, and dielectric constant of soil. In addition, soil resistance is the inverse of soil conductivity. It is usually used to determine the soil moisture or salinity and the distribution boundary of certain soils. These soil properties provide a theoretical basis for measuring soil moisture.

\section{Measurement principles of soil moisture sensor}

There exist various methods for measuring the principles of soil moisture sensors, including gravimetric, tensiometer, neutron, $\gamma$-ray projection, remote sensing, and dielectric methods.

\subsection{Weight method}

The weight method is the drying method. To minimize error, it is usually required to determine the arithmetic mean of the parallel measurement twice or three times, which actually increases as the workload extends the measurement time. The microwave oven baking method does not only save time but also satisfies the actual requirements of the error, which is a more suitable choice for the drying method ${ }^{[9]}$. The drying method is the most commonly used technique for determining soil moisture content. Owing to its simplicity, ease of implementation, and sufficient accuracy, this method is the basic technique for determining soil moisture as well as the basis for the testing and comparison of other methods. However, it has significant disadvantages, i.e., it is time-consuming and laborious, takes a long measurement period, and is not suitable for the continuous dynamic monitoring of soil moisture at a fixed point ${ }^{[10-13]}$.

\subsection{Tensiometer method}

The tensiometer method enables the estimation of the energy contained in soil moisture through monitoring of the movement of water in porous materials that are in contact with the soil. The sensors used in this method usually consisted of two electrodes embedded in a cylindrical particle matrix buried in the soil. This particle matrix balances the soil water content by transferring water from the surrounding soil. The moisture in the sensor was measured by the change in resistance between the two embedded electrodes. Owing to their low cost, particle matrix sensors are widely used in large-scale deployments. However, the tensiometer sensor is limited by its small spatial variability, which is a disadvantage because the lag, under the circumstances, is significant, and the maintenance cost is high ${ }^{[14]}$.

\subsection{Neutron probe method}

In this method, the neutron source is buried in the soil to be tested, and fast neutrons are continuously emitted, which enter the soil medium and collide with various atomic ions. Subsequently, the fast neutrons lose energy and decelerate the atoms. When fast neutrons collide with hydrogen atoms, they lose the most energy and easily decelerate. With an increase in the moisture content of the soil, the hydrogen content and density of slow neutron clouds increase. The neutron meter determines the moisture content in the soil by determining the functional relationship between the density of the slow neutron cloud and water molecules. The neutron probe is used to measure the soil moisture content, without mining and destroying the soil structure, and can be continuously monitored at fixed points, such that the dynamic law of soil moisture movement is obtained at the sample point, which is fast and accurate, and has no hysteresis. However, when the neutron instrument is used, the indoor and outdoor curves are relatively different, and the different physical properties of soil in the field, such as different bulk densities and soil textures, will trigger larger shifts in the curve. Studies have shown that the vertical resolution of the neutron instrument is poor, and obtaining the measurement of the surface layer poses a challenge. In addition, the neutron instrument is expensive, and especially because of radiation hazards to health, it cannot be widely adopted ${ }^{[15-17]}$.

\subsection{Gamma-ray method}

This method is similar to the neutron probe. The Gamma-ray $(\gamma$-ray) transmission method employs a radioactive source such as ${ }^{137} \mathrm{Cs}$ to emit $\gamma$-rays, and the energy of the $\gamma$-rays transmitted through the soil and received by the probe is converted to soil moisture content. The $\gamma$-ray and neutron instrument methods 
share several advantages, such as speed and accuracy, protection of soil structure during measurements, and continuous fixed-point monitoring. However, when compared with that of the neutron instrument, the vertical resolution of the $\gamma$-ray method is higher. Moreover, certain safety concerns limit the application of the method, rendering it inconvenient ${ }^{[18]}$.

\subsection{Infrared remote sensing method}

The soil moisture remote sensing method is used for transmitting or reflecting electromagnetic waves via measurements of the soil surface properties, which provide an effective means for obtaining soil moisture information at a regional scale ${ }^{[19,20]}$.

\subsection{Dielectric method}

Different materials have different dielectric constants. The dielectric constant of the soil is determined by factors such as electromagnetic frequency, temperature, salinity, soil volumetric water content, ratio of bound water to total soil water content, soil density, soil particle shape, and form of moisture content. Because the dielectric constant of water in soil is more significant than that of other substrates and air, it majorly depends on the water content of soil. Therefore, the purpose of measuring the water content of soil can be fulfilled by determining the dielectric constant.

In 1964, the study of Chernyak ${ }^{[21]}$ garnered worldwide attention and was considered the first academic study on the dielectric properties of soils. As a long space medium, soil is composed of solids, water, and air. Generally, the dielectric constants of solids, water, and air are approximately 4, 80, and 1, respectively. In addition, because the dielectric constant of wet soil is mainly determined by the soil water content, it is an effective, fast, simple, and reliable method, which harnesses the dielectric properties of the soil to determine its water content ${ }^{[22]}$. Specifically, it can be divided into measurement methods based on capacitance principle, resistance principle, time domain reflection principle, frequency reflection principle and standing wave principle. Based on this, several types of soil moisture sensors have been developed. Among them are the three common soil moisture sensor products in the market: Time-Domain Reflectometry (TDR), Frequency Domain Reflectometry (FDR), and Standing Wave Ratio (SWR) ${ }^{[23]}$.

\subsubsection{TDR soil moisture sensor}

The theoretical basis for the TDR soil moisture sensor is based on the research conducted by Fellner-Feldegg et al. ${ }^{[24]}$ The method for measuring the soil dielectric constant was developed based on the physical phenomenon that propagation velocity changes with the dielectric constant of the medium. In 1975, Topp et al. ${ }^{[25]}$ introduced the method to the study of soil moisture measurement. The simplified model of the sensor is shown in Figure 1. The signal generator emits a pulse signal; when the signal is transmitted to the probe via the coaxial cable, an impedance mismatch occurs. A part of the signal returns along the original path, and the remaining continues to be transmitted along with the probe. Throughout the probe, impedance mismatch occurs repeatedly at this time. The time difference between the two reflected signals, i.e., the time required for the signal to travel twice along with the probe, is measured using the detection device ${ }^{[10,26]}$

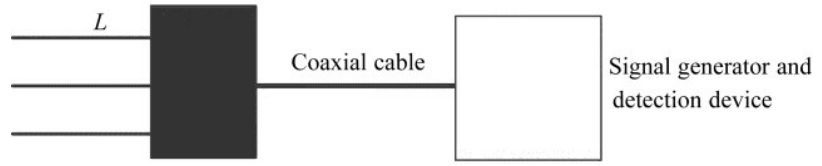

Note: $L$ is the length of the probe, $\mathrm{m}$.

Figure 1 TDR simplified model

\subsubsection{FDR soil moisture sensor}

The FDR-type soil moisture sensor is based on the theoretical study conducted in 1992 by Hilhorst et al. ${ }^{[27]}$ from the Wageningen Agricultural University. Through the conduction of several studies, a method for measuring the soil water content, called frequency domain decomposition, was proposed. It is used for measuring the soil moisture content and the frequency change caused by the sensor alterations in the soil owing to the change in the dielectric constant. The FDR is more flexible than the TDR in terms of probe geometry length and operating frequency. The simplified model of the sensor is illustrated in Figure 2. During the measurement process, the soil acts as a dielectric, and the probe of the sensor is equivalent to that of a capacitor and an external oscillator, which can form a tuning circuit. The capacitance of the sensor is proportional to the dielectric constant of the measured medium between the two levels. The increase in moisture will also increase the equivalent capacitance of the sensor, thus influencing the operating frequency (resonant frequency) of the sensor. The high-frequency oscillator can send out high-frequency signals of tens to hundreds of megahertz, and the resonance frequency can be detected using the high-frequency detection circuit ${ }^{[10,26,28,29]}$.

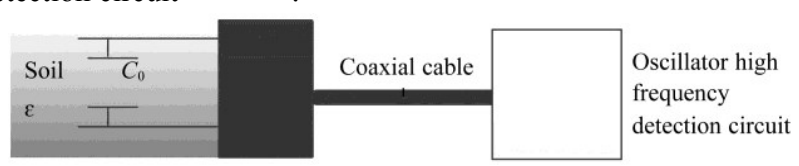

Note: $C_{0}$ is the capacitance when the medium is air; $\varepsilon$ is the relative dielectric constant of the soil.

Figure 2 FDR simplified model

\subsubsection{SWR soil moisture sensor}

The change in the dielectric constant of the three-state mixture can cause a significant change in the SWR of the transmission line. In 1995, Gaskin and Miller ${ }^{[30]}$ proposed a soil moisture measurement method based on the SWR principle in the microwave theory. Its measurement principle is similar to that of the TDR; however, instead of the time difference $(\Delta T)$ between the two reflections of the signal being measured, the SWR of the standing wave is measured in this case. Because this sensor is easier to implement in technology than the other two sensors, its price is considerably lower; however, it is slightly inferior in terms of measurement accuracy and sensor interchangeability. The simplified model of the sensor is illustrated in Figure 3. The signal source generates a $100 \mathrm{MHz}$ signal; when this signal is transmitted along the coaxial cable to the probe, an impedance mismatch occurs. When a part of the signal is reflected along the original path, the incident and reflected signals are superimposed, forming a standing wave. The voltage difference is altered with the change in the probe impedance, which is determined by the dielectric constant of the soil ${ }^{[31]}$.

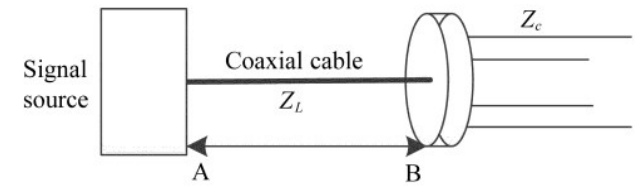

Note: $Z_{L}$ is the characteristic impedance of the transmission line, $\Omega ; Z c$ is the impedance of the probe, $\Omega$; A and $\mathrm{B}$ are the two ends of the transmission line.

Figure 3 SWR Simplified model

The TDR, FDR, and SWR are all based on the dielectric properties of the soil and adopt a variation of Topp's equation ${ }^{[32]}$. Although these sensor types slightly differ in terms of the methods involved, they all determine the water content of a considerably limited soil area next to the sensor. Owing to the spatial 
variability of soil properties, the extrapolation from these significantly small influence ranges to field scales is usually complicated. One way to compensate for this change is to increase the number of sensors deployed; however large-scale deployment is not economically realistic ${ }^{[33]}$.

$$
\Theta=4.3 \times 10^{-6} \varepsilon^{3}-5.5 \times 10^{-4} \varepsilon^{2}+2.92 \times 10^{-2} \varepsilon^{-5.3} \times 10^{-2}
$$

where, $\Theta$ represents the soil volumetric water content, $\mathrm{m}^{3} / \mathrm{m}^{3}$; $\varepsilon$ represents the soil dielectric constant.

\subsubsection{Capacitance principle}

Since the early 1930s, Smith-Rose ${ }^{[34]}$ and Thomas ${ }^{[35]}$ have shown that measuring the dielectric constant of a medium such as soil can potentially indicate changes in water content. When a soil moisture sensor is placed in the soil to measure its moisture content, a square-wave excitation signal is applied to a first-order $\mathrm{RC}$ circuit composed of a resistor and an equivalent capacitance composed of the probe and the medium to be measured. The equivalent capacitance is periodically charged and discharged, so the voltage on the probe exhibits a corresponding periodicity. The periodic waveform signal is converted by the true RMS detector and output in the form of equivalent DC voltage. When the soil moisture content varies, its dielectric constant changes, the equivalent capacitance of the probe also changes. This changes the charge and discharges curves on the equivalent capacitance of the probe, that is, the periodic waveform on the probe changes, and ultimately changes the DC voltage output of the sensor ${ }^{[36-39]}$.

3.6.5 Resistance principle

Resistance-type moisture sensors work by measuring the resistance between electrodes inserted into the medium to determine its moisture content. Due to the different moisture content in the soil, the resistance value of the soil is different, so that the current between the electrodes of the sensor inserted in the soil changes, which is output in the form of DC voltage through amplification and transformation. A precalibrated voltage-moisture curve can then be used to estimate soil moisture content. Traditionally, this method has used a single sensor to measure soil moisture, with the recent introduction of matrix sensors $^{[40-42]}$.

\section{Influencing factors of soil moisture sensor}

\subsection{Influence of inherent factors}

In the study conducted by Chakraborty ${ }^{[43]}$, the influence of the coating and shape of the polymethyl methacrylate-coated sensor on the accuracy and fringe electric field distribution was discussed. Here, four different shapes (triangle, circle, rectangle, and point edge) were adopted to study the electric field distribution and determine the standard root mean square error value to evaluate performance. The simulation and actual results show that the circular soil sample has a good water content measurement performance. Then, a microstrip ring resonator sensor with a four-legged element structure design was developed. The sensing area and measurement accuracy are improved ${ }^{[44]}$.

Iwata et al. ${ }^{[45]}$ evaluated the impact of three sensor installation methods on the output of the capacitive soil moisture sensor and inferred that the installation method significantly influences the output value of the capacitive sensor. Concurrently, installing the sensor to compact the soil increases the output of the sensor. Because this is more significant in the soil, an appropriate calibration equation is an important condition for accurately monitoring the soil moisture content; moreover, the soil moisture sensor should be correctly installed according to the manufacturer's requirements during use. The results obtained from the study of
Zhou et al. ${ }^{[46]}$ showed that the installation depth could influence the stability of the sensor. A flat, thin mm-sized soil moisture sensor (MSMS) was installed in the shallow, middle, and deep positions of the hollow plastic rods with a length of $1.1 \mathrm{~m}$. These were also installed along the depth of the soil to depict changes in soil moisture. The resistance readings of the MSMS along the soil depth were recorded in real-time. Owing to the long-term settlement of the soil after installation, the MSMS in shallow soil is unstable, whereas the MSMS in deep soil exhibits high stability.

\subsection{Influence of environmental factors}

The temperature has a significant influence on the measurement accuracy of the soil moisture sensor. For large temperature changes, a specific equation is required to obtain correct measurement results. Chakraborty et al. ${ }^{[43]}$ studied the effects of external temperature on sensor performance and determined that the output of the sensor was altered under the influence of temperature-related fringe fields. However, in the laboratory, the external temperature remains basically constant and had a negligible effect on the sensor.

The low cost makes it possible for dielectric probes to be widely used, but they are sensitive to temperature, especially $\mathrm{FDR}^{[47]}$. Capacitance sensors are sensitive to soil temperature and work poorly in some soils ${ }^{[48,49]}$. The measurement accuracy of most resistive sensors is prone to drift due to the influence of temperature, so it is necessary to compensate the measured value according to the temperature during field measurement ${ }^{[10,50,51]}$. The Time Domain Reflectometer (TDR) showed a smaller temperature drift ${ }^{[10,50,52-54]}$. Oates et al. ${ }^{[55-58]}$ studied the temperature correction equation or compensation method of different soil moisture sensors under the conditions of temperature change.

The second factor to consider is the influence of soil salinity. Zheng et al. ${ }^{[59]}$ developed a TDR soil moisture sensor with a coated spiral transmission line and tested it in non-saline and saline soils to evaluate its performance. Based on the obtained results, the TDT technology based on the soil moisture sensor exhibits better performance under the condition of saline soil, and its accuracy is similar to that of the $\mathrm{TDR}^{[60]}$. The effect of salinity on the dielectric soil moisture sensor is a function of the dielectric loss of the imaginary part of the complex dielectric constant and is positively correlated with the ionic conductivity of the soil ${ }^{[61]}$. The effects of salinity on dielectric measurements are usually masked at low temperatures ${ }^{[62]}$.

\section{Research improvement and correction of soil moisture sensor based on a dielectric method}

Due to its rapid, convenient, pollution-free, and accurate measurement method, soil moisture sensors based on the dielectric principle have been widely used and attracted significant research interest. The common disadvantages of dielectric sensors are that they are expensive and often require specific calibration of the soil before use. In this study, the improved methods or correction methods, technical principles, precision influencing factors, technical limitations and improved advantages of soil moisture sensors in related studies are compared, as shown in Table 1.

\section{Introduction of main products and performance of soil moisture sensor}

Table 2 summarizes the manufacturers and products of sensors widely used in the market. 
Table 1 Studies on improvement and correction of soil moisture sensor

\begin{tabular}{|c|c|c|c|c|c|c|c|}
\hline Sensor & Used in & Principle & Influence factors & $\begin{array}{l}\text { Calibration model or } \\
\text { improvement aspects }\end{array}$ & Main advantages & Major findings & Reference \\
\hline $\begin{array}{l}\text { Microstrip } \\
\text { ring resonator } \\
\text { sensor }\end{array}$ & $\begin{array}{l}\text { Peat and sandy } \\
\text { soils }\end{array}$ & $\begin{array}{l}\text { Dielectric } \\
\text { principle }\end{array}$ & Shape & $\begin{array}{l}\text { A prediction model using } \\
\text { an analytical ring resonant } \\
\text { model with polynomial } \\
\text { interpolation } \\
\text { approximation via lumped } \\
\text { element model. }\end{array}$ & $\begin{array}{l}\text { The sensing area is } \\
\text { improved and the } \\
\text { measurement accuracy is } \\
\text { improved. }\end{array}$ & $\begin{array}{l}\text { This prediction model was found to agree } \\
\text { well with the commercial dielectric probe } \\
\text { in the dielectric prediction of peat (P28\% } \\
\text { m.c.) and sandy (P10\% m.c.) soils. }\end{array}$ & {$[44]$} \\
\hline $\begin{array}{l}\text { Alow-cost } \\
\text { sensor }\end{array}$ & $\begin{array}{l}\text { Grape field, } \\
\text { mizuna } \\
\text { greenhouse field, } \\
\text { sandy loam }\end{array}$ & $\begin{array}{l}\text { Capacitance } \\
\text { principle }\end{array}$ & Not mentioned & $\begin{array}{l}\text { The copper film substrate. } \\
\text { The circuit was prepared } \\
\text { by etching copper on a } \\
\text { polyethylene terephthalate } \\
\text { (PET) film. }\end{array}$ & $\begin{array}{l}\text { Low cost, which is less } \\
\text { than } \$ 300\end{array}$ & $\begin{array}{l}\text { The sensor captured dynamic changes in } \\
\text { soil moisture at depths of } 10 \mathrm{~cm}, 20 \mathrm{~cm} \text {, } \\
\text { and } 30 \mathrm{~cm} \text { with a period of } 1014 \mathrm{~d} \\
\text { required after sensor installation for the } \\
\text { contact between capacitors and soil to } \\
\text { settle down. }\end{array}$ & {$[64]$} \\
\hline $\begin{array}{l}\text { A novel flat thin } \\
\text { mm-sized } \\
\text { sensor } \\
\text { (MSMS) }\end{array}$ & $\begin{array}{l}\text { Sand,silt,clay } \\
\text { mixtures }\end{array}$ & $\begin{array}{l}\text { Resistance } \\
\text { principle }\end{array}$ & Not mentioned & $\begin{array}{l}\text { Gold compact discs (CD) } \\
\text { etching approach. Linear } \\
\text { regression model. }\end{array}$ & $\begin{array}{l}\text { Small size, compact } \\
\text { structure, easy fabrication } \\
\text { and deployment, ultralow } \\
\text { cost }(<\$ 1 / \text { sensor). }\end{array}$ & $\begin{array}{l}\text { The observation of the sensor surface } \\
\text { indicated anti-scratching capability, } \\
\text { demonstrating high stability for } \\
\text { long-term continuous in situ monitoring } \\
\text { of soil moisture. }\end{array}$ & {$[65]$} \\
\hline $\begin{array}{l}\text { A fringing } \\
\text { field capacitive } \\
\text { sensor }\end{array}$ & $\begin{array}{l}\text { Four soil } \\
\text { samples were } \\
\text { collected from } \\
\text { different } \\
\text { locations }\end{array}$ & $\begin{array}{l}\text { Capacitance } \\
\text { principle }\end{array}$ & Not mentioned & $\begin{array}{l}\text { Electrode thickness, } \\
\text { separation of two adjacent } \\
\text { electrodes, thickness of the } \\
\text { substrate. }\end{array}$ & $\begin{array}{l}\text { It is simple in design, } \\
\text { limited cost, high } \\
\text { sensitivity, large sensing } \\
\text { area and good response } \\
\text { time. }\end{array}$ & $\begin{array}{l}\text { This research studied the optimization } \\
\text { and implementation of a fringing field } \\
\text { capacitive soil moisture sensor using the } \\
\text { printed circuit board technology. }\end{array}$ & {$[66]$} \\
\hline $\begin{array}{l}\text { A sensor based } \\
\text { on graphene } \\
\text { quantum dots } \\
\text { (GQDs) }\end{array}$ & $\begin{array}{l}\text { White clay, } \\
\text { bentonite clay }\end{array}$ & $\begin{array}{l}\text { Resistance } \\
\text { principle }\end{array}$ & Not mentioned & $\begin{array}{l}\text { Improved sensing } \\
\text { materials, MEMS } \\
\text { manufacturing process, } \\
\text { graphene quantum dots } \\
\text { (GQDs) as } \\
\text { zero-dimensional (0D) } \\
\text { graphene. }\end{array}$ & $\begin{array}{l}\text { With very high } \\
\text { sensitivity, simple process } \\
\text { and cheap materials, low } \\
\text { cost sensing unit }\end{array}$ & $\begin{array}{l}\text { The simplicity of the process and use of } \\
\text { cheap GQD material make it an } \\
\text { affordable sensing unit in comparison to } \\
\text { existing soil moisture sensing units. }\end{array}$ & {$[67]$} \\
\hline $\begin{array}{l}\text { The improved } \\
\text { ECH2O sensor }\end{array}$ & $\begin{array}{l}\text { Soil, peat, perlite, } \\
\text { and vinegar } \\
\text { residue }\end{array}$ & $\begin{array}{l}\text { Capacitance } \\
\text { principle }\end{array}$ & Not mentioned & $\begin{array}{l}\text { A two-step calibration } \beta \\
\text { parameter model }\end{array}$ & $\begin{array}{l}\text { High accuracy, simple } \\
\text { calibration process } \\
\text { (two-step calibration } \\
\text { method) and noninvasive } \\
\text { test. }\end{array}$ & $\begin{array}{l}\text { Here, the relationship between the output } \\
\text { of the sensor and the soil water content } \\
\text { calibration model ( } \beta \text { parameter model) } \\
\text { was studied. A two-step calibration } \\
\beta \text {-method was developed. }\end{array}$ & {$[68]$} \\
\hline $\begin{array}{l}\text { Decagon } \\
\text { 10HS }\end{array}$ & $\begin{array}{l}\text { Southwest } \\
\text { Florida } \\
\text { agricultural soils }\end{array}$ & $\begin{array}{l}\text { Dielectric } \\
\text { principle }\end{array}$ & $\begin{array}{l}\text { Compared with } \\
\text { EC-5 and EC-20, } \\
10 \text { HS has less } \\
\text { effect on } \\
\text { temperature and } \\
\text { salinity }^{[47,70]} \text {. }\end{array}$ & $\begin{array}{l}\text { The laboratory-determined } \\
\text { curves for soils specific to } \\
\text { the southwest Florida } \\
\text { region. }\end{array}$ & $\begin{array}{l}\text { Local farmers can use } \\
\text { more precise specific } \\
\text { calibration formulas, and } \\
\text { the cost drops to around } \\
\$ 100\end{array}$ & $\begin{array}{l}\text { The calibration equation developed } \\
\text { during this research for southwest Florida } \\
\text { could allow for more widespread use of } \\
\text { 10HS in the region. }\end{array}$ & [69] \\
\hline 10 HS Sensor & $\begin{array}{l}\text { Sandy soils, the } \\
\text { clay soils }\end{array}$ & $\begin{array}{l}\text { Capacitance } \\
\text { principle }\end{array}$ & $\begin{array}{l}\text { It is sensitive to } \\
\text { soil types. } \\
\text { Required specific } \\
\text { calibration }\end{array}$ & $\begin{array}{l}\text { Two-point and multipoint } \\
\text { specific calibration } \\
\text { equations }\end{array}$ & Not mentioned & $\begin{array}{l}\text { The response of the } 10 \text { HS sensor in } \\
\text { bi-layered systems was also investigated. } \\
\text { The results obtained from the } \\
\text { experiments suggested that there is a } \\
\text { distinct instrument sensitivity to soil type, } \\
\text { thus indicating the necessity for } \\
\text { individual soil calibration. }\end{array}$ & [71] \\
\hline $\begin{array}{l}\text { GS } 1 \text {,Stevens } \\
\text { Hydraprobe II } \\
\text { TDR-315 }\end{array}$ & $\begin{array}{l}\text { Three sandy } \\
\text { loam soils from } \\
\text { Harper Adams } \\
\text { University }\end{array}$ & $\begin{array}{l}\text { Dielectric } \\
\text { principle }\end{array}$ & $\begin{array}{l}\text { Both temperature } \\
\text { and humidity } \\
\text { matter. Required } \\
\text { specific calibration }\end{array}$ & $\begin{array}{l}\text { Calibration equations } \\
\text { using linear least squares } \\
\text { regression }\end{array}$ & $\begin{array}{l}\text { Three sensors were } \\
\text { evaluated and required } \\
\text { specific calibration }\end{array}$ & $\begin{array}{l}\text { The calibration equation developed in the } \\
\text { laboratory improves the accuracy of the } \\
\text { evaluated soil moisture sensor. }\end{array}$ & {$[72]$} \\
\hline $\begin{array}{l}\text { TDR315, } \\
\text { CS655,GS1, } \\
\text { SM100, and } \\
\text { CropX }\end{array}$ & $\begin{array}{l}\text { Lower salinity } \\
\text { and clay content, } \\
\text { higher salinity } \\
\text { and clay content }\end{array}$ & $\begin{array}{l}\text { Dielectric } \\
\text { principle }\end{array}$ & Not mentioned & Not mentioned & Not mentioned & $\begin{array}{l}\text { The TDR } 315 \text {, CS655, and GS1 sensors } \\
\text { had acceptable accuracies for managing } \\
\text { irrigations at the site with low salinity and } \\
\text { low clay content (LSLC) based on root } \\
\text { mean square error (RMSE). }\end{array}$ & {$[73]$} \\
\hline SKU:SEN0193 & $\begin{array}{l}\text { Soil with sandy } \\
\text { loam structure } \\
\text { (39.3\% clays, } \\
47.5 \% \text { sand, } \\
13.2 \% \text { silt) }\end{array}$ & $\begin{array}{l}\text { Capacitance } \\
\text { principle }\end{array}$ & $\begin{array}{l}\text { It requires specific } \\
\text { calibration to } \\
\text { facilitate local soil } \\
\text { applications. }\end{array}$ & Not mentioned & $\begin{array}{l}\text { To solve the problems } \\
\text { existing in the application } \\
\text { of conductance sensors. } \\
\text { A low-cost soil moisture } \\
\text { sensor }\end{array}$ & $\begin{array}{l}\text { There is a direct relationship between the } \\
\text { soil moisture content }(y) \text { and the sensor } \\
\text { response }(x) \text {, the sensor performs well so } \\
\text { it can be used to measure the moisture } \\
\text { content of sandy clay soil samples. }\end{array}$ & {$[74]$} \\
\hline SKU:SEN0193 & $\begin{array}{l}\text { Silica sandy } \\
\text { soil }\end{array}$ & $\begin{array}{l}\text { Capacitance } \\
\text { principle }\end{array}$ & $\begin{array}{l}\text { The preparation of } \\
\text { the sample impacts } \\
\text { the measurement } \\
\text { of the capacitive } \\
\text { sensor. }\end{array}$ & Not mentioned & Not mentioned & $\begin{array}{l}\text { This type of capacitive sensor yielded a } \\
\text { reliable relationship between output } \\
\text { voltage and gravimetric water content at } \\
\text { least for a well-defined type of soil with a } \\
\text { constant solid matter to volume ratio. }\end{array}$ & {$[75]$} \\
\hline
\end{tabular}




\begin{tabular}{|c|c|c|c|c|c|c|c|}
\hline Sensor & Used in & Principle & Influence factors & $\begin{array}{l}\text { Calibration model or } \\
\text { improvement aspects }\end{array}$ & Main advantages & Major findings & Reference \\
\hline SKU:SEN0193 & $\begin{array}{l}\text { Organic-rich } \\
\text { gardening soil }\end{array}$ & $\begin{array}{l}\text { Capacitance } \\
\text { principle }\end{array}$ & Not mentioned & $\begin{array}{l}\text { The developed } \\
\text { soil-specific calibration } \\
\text { function for gardening soil }\end{array}$ & $\begin{array}{l}\text { The total cost of the } \\
\text { developed soil moisture } \\
\text { monitoring system (US\$ } \\
\text { in 2019) is } \$ 45.7\end{array}$ & $\begin{array}{l}\text { A prototype was developed for } \\
\text { automated soil moisture monitoring using } \\
\text { a low-cost capacitive soil moisture sensor } \\
\text { (SKU:SEN0193) for data acquisition, } \\
\text { connected to the internet. }\end{array}$ & {$[76]$} \\
\hline $\begin{array}{l}\text { A fully } \\
\text { automatic } \\
\text { high-resolution } \\
\text { sensor }\end{array}$ & $\begin{array}{l}\text { Greenhouse, } \\
\text { CAU grassland, } \\
\text { Yunnan soils }\end{array}$ & $\begin{array}{l}\text { Dielectric } \\
\text { principle }\end{array}$ & Depth & $\begin{array}{l}\text { Three linear calibration } \\
\text { models were established } \\
\text { under different soil } \\
\text { conditions. }\end{array}$ & $\begin{array}{l}\text { A low-cost sensor for SM } \\
\text { monitoring at three } \\
\text { vertical depths }\end{array}$ & $\begin{array}{l}\text { Each depth of the sensor displayed } \\
\text { acceptable validation statistics. The } \\
\text { linear fitting coefficients }\left(R^{2}\right) \text { ranged } \\
\text { from } 0.95 \text { to } 0.99 \text {. }\end{array}$ & [77] \\
\hline A TDM sensor & Not mentioned & TDM & Not mentioned & $\begin{array}{l}\text { The calibration model is } \\
\text { established by a } \\
\text { polynomial (third-order) } \\
\text { fitting equation. }\end{array}$ & $\begin{array}{l}\text { Low-cost and } \\
\text { high-resolution }\end{array}$ & $\begin{array}{l}\text { The sensor can be used for continuous } \\
\text { SM measurements, which will be } \\
\text { beneficial for planning irrigation } \\
\text { practices in arid and irrigated areas. }\end{array}$ & {$[78]$} \\
\hline $\begin{array}{l}\text { A new } \\
\text { capacitive } \\
\text { sensor }\end{array}$ & $\begin{array}{l}\text { Homogeneous } \\
\text { silt-clay-loam } \\
\text { soil }\end{array}$ & $\begin{array}{l}\text { Capacitance } \\
\text { principle }\end{array}$ & $\begin{array}{l}\text { It is less affected } \\
\text { by temperature. }\end{array}$ & Not mentioned & $\begin{array}{l}\text { The cost is reduced while } \\
\text { maintaining sufficient } \\
\text { accuracy }\end{array}$ & $\begin{array}{l}\text { A new capacitive low-cost soil moisture } \\
\text { sensor incorporates SDI-12 } \\
\text { communication, allowing one to select } \\
\text { the calibration equation for different soils. }\end{array}$ & [79] \\
\hline $\begin{array}{l}\text { A homemade } \\
\text { low-cost sensor }\end{array}$ & Not mentioned & $\begin{array}{l}\text { Resistance } \\
\text { principle }\end{array}$ & Not mentioned & Not mentioned & $\begin{array}{l}\text { This method has the } \\
\text { advantages of low } \\
\text { equipment cost and } \\
\text { simple operation }\end{array}$ & $\begin{array}{l}\text { Measuring soil moisture along depth } \\
\text { helps determine the appropriate time for } \\
\text { water supply to reach crop roots. }\end{array}$ & {$[80]$} \\
\hline
\end{tabular}

Table 2 Major products and performance of soil moisture sensor

\begin{tabular}{|c|c|c|c|c|}
\hline No. & $\begin{array}{c}\text { Manufacturer } \\
\text { (Company, website) }\end{array}$ & Country & Representative product & Brief description \\
\hline \multirow{2}{*}{1} & \multirow{2}{*}{$\begin{array}{l}\text { Campbell Scientific } \\
\text { www.campbellsci.com }\end{array}$} & \multirow{2}{*}{ USA } & SoilVUE10 & $\begin{array}{l}\text { Used for the measurement of soil water content and estimation of the amount of stored } \\
\text { water. It is installed for rapid and long-term measurements. }\end{array}$ \\
\hline & & & CS650/655/616 & $\begin{array}{l}\text { The CS650 is a multiparameter smart sensor that adopts innovative techniques for } \\
\text { monitoring soil volumetric water content, bulk electrical conductivity, and temperature. }\end{array}$ \\
\hline 2 & $\begin{array}{l}\text { Acclima company } \\
\text { www.acclima.com }\end{array}$ & USA & TDR-315H/310H/305H & $\begin{array}{l}\text { Integrated time-domain reflectometers that combine ultra-high-speed waveform } \\
\text { generation and digitization functions, high-precision 5-ps resolution time base, and } \\
\text { highly complex waveform digitization and analysis firmware. }\end{array}$ \\
\hline 3 & $\begin{array}{c}\text { Dynamax } \\
\text { www.dynamax.com }\end{array}$ & USA & SM150T & $\begin{array}{l}\text { Enables stable, robust, and reliable performance at a very high expense. The } \\
\text { SM150T's advanced patented electronics and rugged construction result in the } \\
\text { realization of a highly reliable sensor with special salinity and temperature stability. }\end{array}$ \\
\hline \multirow{2}{*}{4} & \multirow{2}{*}{$\begin{array}{c}\text { Decagon Devices } \\
\text { www.metergroup.com }\end{array}$} & \multirow{2}{*}{ USA } & ECH2O 10HS & Averages varying soil moisture and characterize spatial variability. \\
\hline & & & ECH2O EC-5/5TE/GS1 & Delivers research-grade accuracy at an economical price. \\
\hline 5 & $\begin{array}{c}\text { Irrometer } \\
\text { www.irrometer.com }\end{array}$ & USA & $\begin{array}{l}\text { Watermark Soil Moisture } \\
\text { Sensor }\end{array}$ & $\begin{array}{l}\text { A solid-state electrical resistance-sensing device is used to measure soil water tension } \\
\text { and resistance. }\end{array}$ \\
\hline 6 & $\begin{array}{l}\text { Enviroprosoilprobes } \\
\text { www.enviroprosoilprobes.com }\end{array}$ & Australia & $\begin{array}{l}\text { EnviroPro } \\
\text { SDI-12/EP100G/EP100GL }\end{array}$ & $\begin{array}{l}\text { EnviroPro sensors are uniquely designed to have a field of influence significantly } \\
\text { larger than that of other capacitance probes of similar diameter, whereby more } \\
\text { meaningful measurements of the local soil can be obtained. }\end{array}$ \\
\hline 7 & $\begin{array}{l}\text { Edaphic scientific } \\
\text { www.edaphic.com.au }\end{array}$ & Australia & TEROS-10/11/12 & $\begin{array}{l}\text { A calibrated, robust, and reliable water content sensor ideal for soils or substrates in the } \\
\text { field, glasshouse, pots, or laboratory analog output to connect to most data loggers' } \\
\text { analog output and portable measurements with the Procheck handheld meter. }\end{array}$ \\
\hline 8 & $\begin{array}{l}\text { Delta-T Devices } \\
\text { www.delta-t.co.uk }\end{array}$ & British & $\begin{array}{l}\text { SM150T/ML3 } \\
\text { ThetaProbe/WET-2 }\end{array}$ & $\begin{array}{l}\text { Have optimal accuracy, stability, and reliability for the measurement of additional } \\
\text { parameters. It is suited to a large range of non-soil substrates and growing media, } \\
\text { including coir, mineral wool, and peat. }\end{array}$ \\
\hline 9 & $\begin{array}{l}\text { Hydronix } \\
\text { www.hydronix.com }\end{array}$ & British & Hydro-Mix XT/HT & $\begin{array}{l}\text { A rugged, flush-mounted microwave moisture measurement sensor for mixers and } \\
\text { conveyors in process control environments. }\end{array}$ \\
\hline 10 & $\begin{array}{c}\text { DFRobot } \\
\text { www.dfrobot.com }\end{array}$ & China & SKU:SEN0193 & $\begin{array}{l}\text { Uses the principle of capacitive induction to detect soil moisture. Under the protection } \\
\text { of insulating paint, the circuit does not directly contact the wet soil. This way, the } \\
\text { working life of the circuit is longer. The sensor built-in voltage regulator chip. }\end{array}$ \\
\hline \multirow[t]{2}{*}{11} & \multirow[t]{2}{*}{$\begin{array}{c}\text { Imko } \\
\text { www.imko.de/en }\end{array}$} & \multirow[t]{2}{*}{ Germany } & $\begin{array}{l}\text { Soil moisture probes } \\
\text { TRIME-PICO } 64 / 32\end{array}$ & $\begin{array}{l}\text { Suitable for field operations for measuring soil moisture and temperature as well as the } \\
\text { conductivity of soil and other porous materials. The PICO32 has a probe and } \\
\text { evaluation electronics integrated into a sensor to achieve maximum accuracy. }\end{array}$ \\
\hline & & & HD2 & Used for measuring the moisture in sand, gravel, and other aggregates. \\
\hline 12 & $\begin{array}{l}\text { Adaptive AgroTech } \\
\text { Consultancy Int } \\
\text { www.AdaptiveAgroTech.com }\end{array}$ & Germany & ADP-SMC2020 & $\begin{array}{l}\text { A capacitive type soil moisture sensor with onboard noise filtering that is specially } \\
\text { designed for harsh field conditions, and for easy interfacing with a variety of } 8 \text {-bit and } \\
\text { 32-bit microcontrollers. It is calibrated for different soil types and generates raw and } \\
\text { relative data output. }\end{array}$ \\
\hline
\end{tabular}

\section{Cases in practical application}

Most soil moisture sensors such as 10HS measure the dielectric constant of the soil using capacitance technology in order to find its volumetric water content (VWC), for scientific research and greenhouse applications. These sensors usually use $70 \mathrm{MHz}$ frequency, which minimizes salinity and textural effects, providing high-resolution measurements that allow daily or hourly tracking of soil moisture content by sending analog voltage that is proportional to water content. These sensors have low sensitivity 
to salt and temperature, and are low power consumption. They can be connected directly or via interfaces to IoT boards for real-time monitoring. Light level sensor, also known as Light Dependent Resistor (LDR) is an active sensor that is made of high accuracy, fast response, high resistance semiconductor which is sensitive to light. It decreases resistance with respect to receiving luminosity (light) on the component's sensitive surface. The resistance of a photo-resistor decreases with increasing incident light intensity (it exhibits photoconductivity). In the dark, a photo-resistor can have a resistance as high as several mega ohms (M $\Omega)$, while in the light, a photo-resistor can have a resistance as low as a few hundred ohms. It should be noted that the raw output data from this sensor need to be calibrated for specific interpretation. The SQ-110 sensor, specifically calibrated for the detection of solar radiation, provides at its output a voltage proportional to the intensity of the light in the visible range of the spectrum, a key parameter in photosynthesis processes. The waterproof DS18b20 is a robust and corrosion-free sensor that can be used for measuring soil temperature. This sensor comes with different cable lengths of $1.8 \mathrm{~m}$ and $3 \mathrm{~m}$ and provides 9-bit Celsius temperature measurements. The DS18B20 communicates over a 1 -Wire bus that by definition requires only one data line (and ground) for communication with the connectivity board. Another temperature sensor, Pt-1000, works based on the resistance that varies between approximately $920 \Omega$ and $1200 \Omega$ in the range considered useful in greenhouse applications $\left(-20^{\circ} \mathrm{C}-50^{\circ} \mathrm{C}\right.$, approximately), which results in too low variations of voltage at
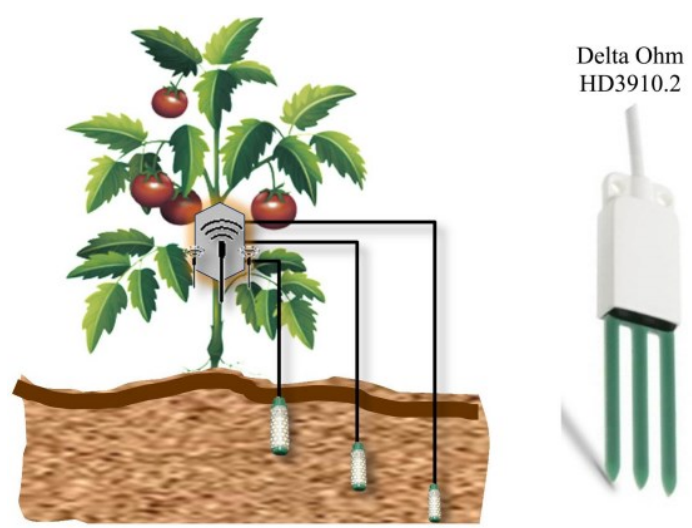

Figure 4 Most widely used soil moisture sensor interfaced with data loggers and wireless monitoring systems for digital agriculture applications ${ }^{[81]}$
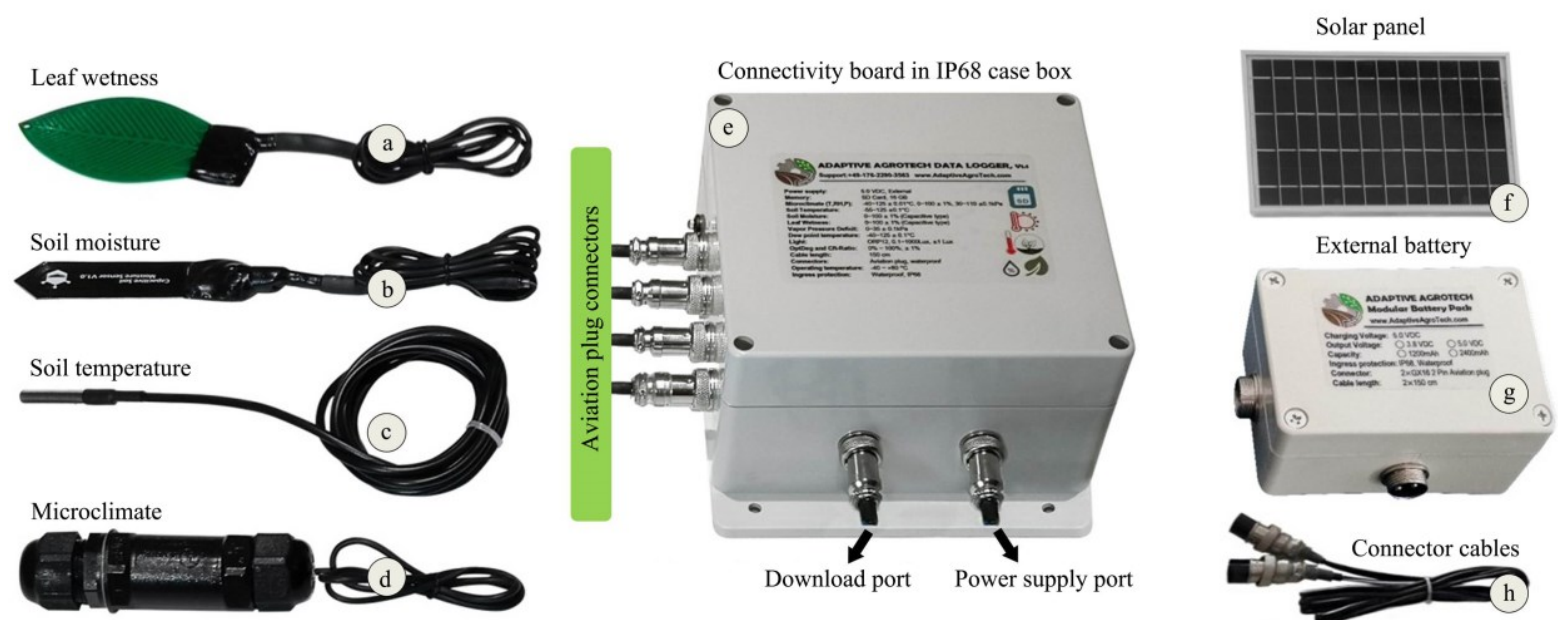

Note: a. Leaf wetness sensor $\quad$ b. Soil moisture sensor $\quad$ c. Soil temperature sensor d. Microclimate sensor e. Main connectivity board with 32 GB onboard memory, USB, WiFi, and LoRa $868 \mathrm{Mhz}$ communication interface f. Solar panel g. Rechargeable external battery h. Aviation plug connector cables. Image by courtesy of Adaptive AgroTech.

Figure 5 Hybrid multichannel data logger system with IoT connectivity and modular components 


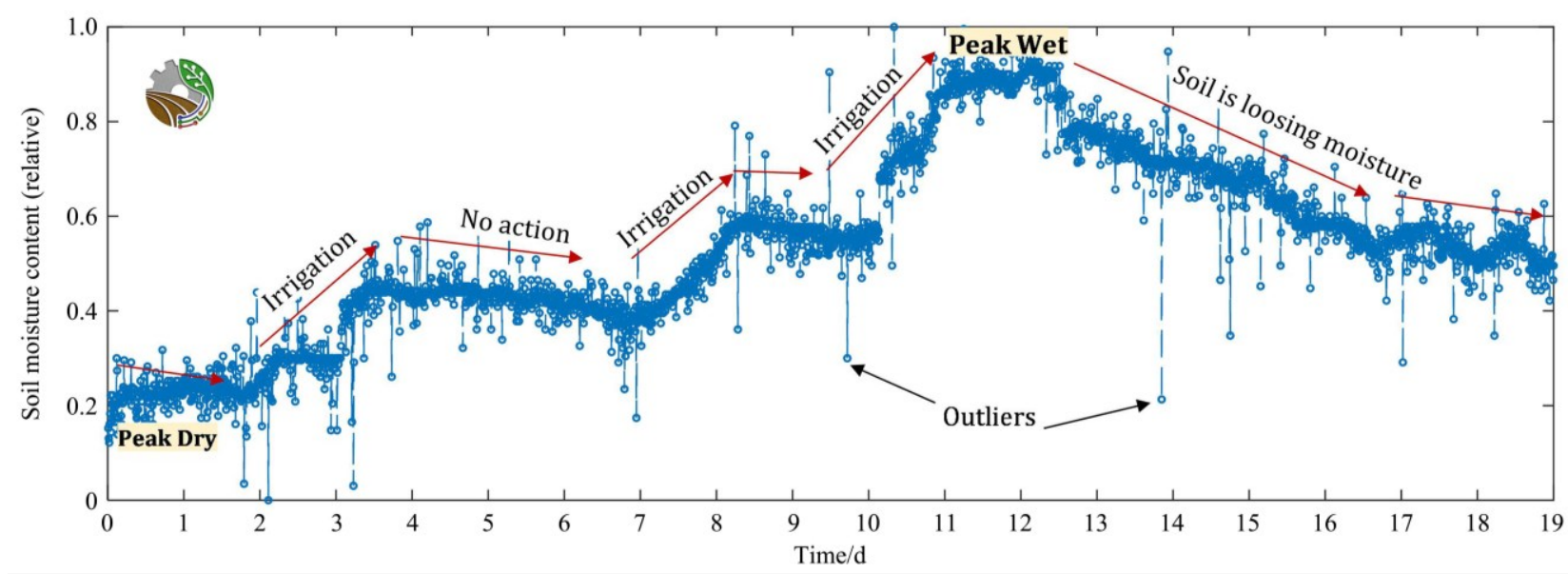

Note: The data were collected between Apr. 05 and Apr. 242021 in open-field cultivation of tomatoes in the province of Hamedan, Iran. Image by courtesy of Adaptive AgroTech.

Figure 6 Relative soil moisture data of samples ${ }^{[81]}$

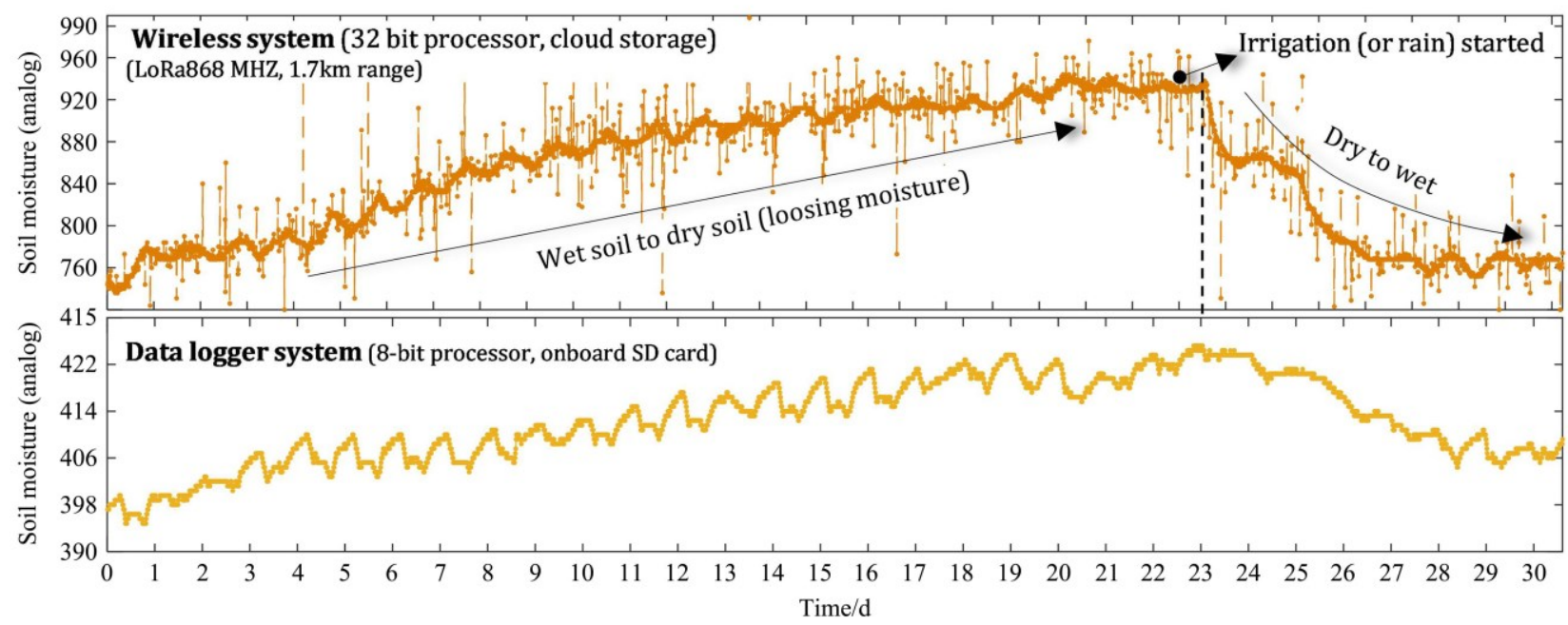

Note: The data were collected every 10 min for $30 \mathrm{~d}$ using a 32-bit wireless system and an 8-bit hybrid data logger in Aug.2020 from a berry field in the Brandenburg state of Germany.

Figure 7 Raw soil moisture data of samples ${ }^{[6]}$

\section{Development trend of soil moisture sensor}

The soil moisture sensor is a considerably mature technology, which has increasingly attracted the attention of scientists in the fields of soil science, agronomy, and engineering. Presently, in the development of soil moisture sensor, their application, calibration formula, and accuracy vary, and the difference among different soil types is not considered.

Owing to the advanced development of information technology and IoT, several researchers have continued to deepen their understanding of the physical mechanism of moisture testing and the continuous improvement of testing methods. Moreover, novel sensing materials have been developed, thus improving the accuracy and application range of sensors. Sensors for different application scenarios have also been fabricated. Moreover, different calibration formulas were derived for different soil textures to improve detection accuracy. Specific calibration, low cost, and continuous monitoring integrated into smart irrigation and IoT systems are the direction of development for soil moisture sensors.

The accuracy of the sensors is fundamental to their widespread use, from integrated applications where economic considerations are considered to research applications where accurate soil moisture data are required. The calibrations provided by commercial sensors do not necessarily meet the needs of all applications, so soil-specific calibrations, whether developed in the field or the laboratory, often improve sensor accuracy ${ }^{[70,82]}$. The study of Nagahage et al. ${ }^{[76]}$ carried out a specific soil calibration.

Low cost is an important aspect of every sensor technology development. The premise is that soil moisture sensors can be popularized in large-scale applications. At present, there are two main technology routes to achieve low cost. One is to reduce the hardware cost of the sensor, the other is to improve the accuracy of the sensor by optimizing the correction algorithm. Commercial sensors are expensive for most farmers, for example, some TDR devices cost as much as $\$ 3000$. Capacitive soil moisture sensors are a better substitute for $\operatorname{TDR}^{[39,83-86]}$. Kojima developed a low-cost sensor using capacitors on a film substrate and a capacitive touch-integrated circuit, which reduced the cost to $\$ 300^{[64]}$. The research of Spelman led to the ability of local farmers to use more precise specific calibration formulas, with a drop in cost to around $\$ 100^{[69]}$. The above methods have significantly reduced the cost of soil moisture sensors.

The automatic scheduling of intelligent irrigation systems needs to be based on the parameters obtained by sensor equipment, and the selection of sensors needs to comprehensively consider cost, operability, integration, performance stability and accuracy. Different application scenarios of intelligent irrigation systems also 
lead to different emphases on sensor characteristics, such as sensitivity to vertical or horizontal soil moisture change, performance stability of continuous detection of soil moisture content, and sensitivity to soil moisture change. In order to meet the requirement of intelligent irrigation for accurate detection of soil moisture in the vertical profile, a soil moisture sensor based on the principle of high frequency capacitance was designed. Through calibration tests and field tests, it is necessary to accurately measure the soil profile moisture content in real-time and understand spatial water use, in order to provide a basis for selecting the optimal irrigation time and threshold and carrying out precision irrigation ${ }^{[87,88]}$. Gao et al. ${ }^{[89]}$ carried out design and experiment on a soil profile moisture sensor. Saeed et al. ${ }^{[78]}$ developed a TDM sensor for simultaneous detection of SM at four soil depths $(10 \mathrm{~cm}, 20 \mathrm{~cm}, 40 \mathrm{~cm}$, and $60 \mathrm{~cm})$. The sensitivity of the sensor was tested in a micro-controlled irrigation system. The results showed that the sensor can be used for continuous SM measurements, which will be beneficial for planning irrigation practices in arid and irrigated areas. The location and accuracy of soil moisture sensors affect the performance of a surface drip irrigation dispatching system based on soil moisture. A simulated drip irrigation automatic scheduling system based on soil moisture was designed to support the application of soil moisture sensors in intelligent irrigation ${ }^{[0]}$.

At present, the area of agricultural planting is continuing to increase, which therefore increases the control area of agricultural intelligent systems. This situation leads to the need for the sensor, as the front-end of the agricultural IoT, to have network communication ability. Sensors with a transmission function are the basis of continuous data acquisition in real-time. The application sensor can be installed in a distributed node for IoT applications. The development and integration of other sensors in the agricultural IoT are necessary for the development of digital agriculture. Shamshiri et al. ${ }^{[6]}$ found that, in the IoT real-time acquisition system deployed in berry orchards, the soil moisture sensor played an indispensable role in the real-time and accurate acquisition of soil moisture status, and provided accurate soil moisture information for microclimate monitoring. Wild et al. ${ }^{[91]}$ developed the simultaneous measurement of air, surface and soil temperatures by three independent sensors. TMS data loggers have large memory and long battery life, making them suitable for long-term microclimate measurements in the field. Data were collected at $15 \mathrm{~min}$ intervals, and there was enough memory to last nearly 15 years, providing key data on microclimatic conditions that influenced biological processes in the face of climate change. The sensor was combined with the automatic soil moisture monitoring system and connected to the Internet for data acquisition. Athani et al. ${ }^{[92]}$ took a specialized approach to designing soil monitoring systems, designing a cost-effective and automated model to monitor and regulate moisture levels in soil samples to meet the needs of technology-illiterate rural farmers.

\section{Acknowledgements}

The authors would like to acknowledge that their colleagues for their support of this work, as well as the editorial comments from Adaptive AgroTech Consultancy Int. This work was supported by the National Natural Science Foundation of China (Grant No. 31801669), the Research and Development Program of Shandong Province (Grant No. 2019GSF111035), and the Government-sponsored Visiting Scholar Research Program.

\section{[References]}

[1] Knighton D. Thirsty world. The World Today, 2002; 58(8-9): 13-14.

[2] Kinzli K D, Manana N, Oad R. Comparison of laboratory and field calibration of a soil-moisture capacitance probe for various soils. Journal of Irrigation and Drainage Engineering, 2012; 138(4): 310-321.

[3] WBCSD Water Facts \& Trends. Available: http://www.wbcsd.org/home.aspx. Accessed on [2020-11-10].

[4] Peng S Q, Zhong Y H, Cui Y, Yang C R. Technical manual of farmland soil moisture monitoring. Beijing: China Agricultural Science and Technology Press, 2008; 159p. (in Chinese)

[5] Soil biochemistry. In: Encyclopedia of Chinese Agriculture, Soil Volume, Chinese Agricultural Encyclopedia Compiling Committee, Beijing: Agricultural Press, 1996; pp.362-364.

[6] Shamshiri R R, Weltzien C. Development and field evaluation of a multichannel LoRa sensor for IoT monitoring in berry orchards. In: Meyer-Aurich A. et al. Informations-und Kommunikationstechnologien in kritischen Zeiten. Lecture Notes in Informatics (LNI). Gesellschaft für Informatik, Bonn, 2021; pp.289-294.

[7] Yu H, Xie D T, Luo Y Z, Zhang Z L, Zhang S R, Li W L, et al. Accuracy analysis and evaluation of four common soil moisture sensors. Agricultural Engineering, 2019; 9(6): 26-32. (in Chinese)

[8] Yao S X, Zhang T H, Zhao C C, Liu X P. Spatio-temporal variability of soil moisture in different dunes of Horqin sandy land. Journal of Soil and Water Conservation, 2012; 26(1): 251-254, 258. (in Chinese)

[9] Shi Z, Guo Y, Jin X, Wu H X. Advancement in study on proximal soil sensing. Acta Pedologica Sinica, 2011; 48(6): 1274-1281. (in Chinese)

[10] Su S L, Singh D N, Baghini M S. A critical review of soil moisture measurement. Measurement, 2014; 54: 92-105.

[11] Njoku E G, Entekhabi D. Passive microwave remote sensing of soil moisture. Journal of Hydrology, 1996; 184(1-2): 101-129.

[12] Jackson T J. Measuring surface soil moisture using passive microwave remote sensing. Hydrological Processes, 1993; 7(2): 139-152.

[13] Carlson T. An overview of the triangle method for estimating surface evapotranspiration and soil moisture from satellite imagery. Sensors, 2007; 7(8): 1612-1629.

[14] Chow L, Xing Z, Rees H W, Meng F R, Monteith J, Stevens L. Field performance of nine soil water content sensors on a sandy loam soil in New Brunswick, Maritime Region, Canada. Sensors, 2009; 9(11): 9398-9413.

[15] Gardner W, Kirkham D. Determination of soil moisture by neutron scattering. Soil Science, 1952; 73(5): 391-402.

[16] Van Bavel C H M, Underwood N, Swanson R W. Soil moisture measurement by neutron moderation. Soil Science, 1956; 82(1): 29-42.

[17] Greacen E L. Soil water assessment by the neutron method. Agricultura Water Management, 1983; 6(1): 79. doi: 10.1016/0378-3774(83)90027-6.

[18] Zhang L R, Qiao J. Application of $\gamma$ transmission method in moisture measurement of landslide model. Yangtze River, 2012; 43(21): 45-48. (in Chinese)

[19] Yang T, Gong H L, Li X J, Zhao W G, Meng D. Progress of soil moisture monitoring by remote sensing. Acta Ecologica Sinica, 2010; 30(22): 6264-6277. (in Chinese)

[20] Yin Z, Lei T W, Yan Q H, Chen Z P, Dong Y Q. A near-infrared reflectance sensor for soil surface moisture measurement. Computers and Electronics in Agriculture, 2003; 99: 101-107.

[21] Chernyak G Y. Chapter III. Dielectric methods for investigating mois soils. In: Works of the all-union research institute of hydrology and engineering geology. New Ser. No.5. Israel Program for Scientific Translations, Jerusalem, 1967; pp.19-22.

[22] Dean T J, Bell J P, Baty A J B. Soil moisture measurement by an improved capacitance technique, part I. Sensor design and performance. Journal of Hydrology, 1987; 93(1-2): 67-68.

[23] Zhang Y, Ma Y H, Jiang Z H, Tan C J, Wang C S. Progress on research and application of rapid measurement of soil moisture sensor. Chinese Agricultural Science Bulletin, 2014; 30(5): 170-174. (In Chinese)

[24] Fellner-Feldegg H. Measurement of dielectrics in the time domain. The Journal of Physical Chemistry, 1969; 73(3): 616-623.

[25] Topp G C, Davis J L, Annan A P. Electromagnetic determination of soil water content: Measurements in coaxial transmission lines. Water Resources Research, 1980; 16(3): 574-582.

[26] Zazueta F S, Xin J N. Soil moisture sensors. Florida Cooperative Extension Service, Bulletin, 1994; 292: 1-11

[27] Hilhorst M A, Breugel K V A N, Plumgraaff D J M H, Kroese W S. Dielectric sensors used in environmental and construction engineering. MRS Online Proceedings Library, 1995; 411: 401-406. 
[28] Jiang Z H, Tan C J, Zhi X Q, Wang C S, Ma Y H. Development of portable soil moisture detector based on principle of frequency domain reflectometry. Transducer and Microsystem Technologies, 2012; 32(1): 79-82. (in Chinese)

[29] Stacheder M, Koeniger F, Schuhmann R. New dielectric sensors and sensing techniques for soil and snow moisture measurements. Sensors, 2009; 9(4): 2951-2967.

[30] Gaskin G J, Miller J D. Measurement of soil water content using a simplified impedance measuring. Journal of Agricultural Engineering Research, 1996; 63(2): 153-159.

[31] Zhao Y D, Gao C, Zhang X, Xu Q. Non-destructive measurement of plant stem water content based on standing wave ratio. Transactions of the CSAM, 2016; 47(1): 310-316. (in Chinese)

[32] Chávez J L, Evett S. Using soil water sensors to improve irrigation management. In: Proceedings of the $24^{\text {th }}$ Annual Central Plains Irrigation Conference, Colby, Kansas: Colorado State University. Libraries, 2012; pp.187-202.

[33] Raper T B. In-season drought monitoring: Testing instrumentation and developing methods of measurement analysis. Doctoral dissertation, 2014; $158 \mathrm{p}$.

[34] Smith-Rose R L. The electrical properties of soils for alternating currents at radio frequencies. Proceedings of the Royal Society A.1933; 140(841): 359-377.

[35] Thomas A M. In situ measurement of moisture in soil and similar substances by 'fringe' capacitance. Journal of Scientific Instruments, 1966; 43(1): 21-27.

[36] Kelleners T J, Soppe R W O, Robinson D A, Schaap M G. Calibration of capacitance probe sensors using electric circuit theory. Soil Science Society of America Journal, 2004; 68(2): 430-439.

[37] Li J N, Hong T S, Feng R J, Yue X J, Luo Y Q. High-frequency capacitive soil water content sensor based on detecting of true root mean square. Transactions of the CSAE, 2011; 27(8): 216-221. (in Chinese)

[38] Fares A, Polyakov V. Advances in crop water management using capacitive water sensors. Advances in Agronomy, 2006; 90: 43-77.

[39] Dean T J, Bell J P, Baty A J B. Soil moisture measurement by an improved capacitance technique, Part I. Sensor design and performance. Journal of Hydrology, 1987; 93(1-2): 67-78.

[40] McCann I R, Kincaid D C, Wang D. Operational characteristics of the watermark model 200 soil water potential sensor for irrigation management. Applied Engineering in Agriculture, 1992; 8(5): 603-609.

[41] Gawande N A, Reinhart D R, Thomas P A, McCreanor P T, Townsend T G. Municipal solid waste in situ moisture content measurement using an electrical resistance sensor. Waste Management, 2003; 23(7): 667-674.

[42] Dias P C, Cadavid D, Ortega S, Ruiz A, França M B M, Morais F J O, et al. Autonomous soil moisture sensor based on nanostructured thermosensitive resistors powered by an integrated thermoelectric generator. Sensors and actuators A: Physical, 2016; 239: 1-7.

[43] Chakraborty M, Kalita A, Biswas K. PMMA-coated capacitive type soil moisture sensor: Design, fabrication, and testing. IEEE Transactions on Instrumentation and Measurement, 2018; 68(1): 189-196.

[44] Then Y L, You K Y, Dimon M N, Lee C Y. A modified microstrip ring resonator sensor with lumped element modeling for soil moisture and dielectric predictions measurement. Measurement, 2016; 94: 119-125.

[45] Iwata $Y$, Miyamoto T, Kameyama K, Nishiya M. Effect of sensor installation on the accurate measurement of soil water content. European Journal of Soil Science, 2017; 68: 817-828.

[46] Zhou W C, Xu Z H, Ross D, Dignan J, Fan Y Z, Huang Y K, et al. Towards water-saving irrigation methodology: Field test of soil moisture profiling using flat thin mm-sized soil moisture sensors (MSMSs). Sensors and Actuators B: Chemical, 2019; 298: 126857. doi: 10.1016/ j.snb.2019.126857.

[47] Kizito F, Campbell C S, Campbell G S, Cobos D R, Teare B L, Carter B, et al. Frequency, electrical conductivity and temperature analysis of a low-cost capacitance soil moisture sensor. Journal of Hydrology, 2008; 352(3-4): 367-378.

[48] Seyfried M S, Grant L E. Temperature effects on soil dielectric properties measured at $50 \mathrm{MHz}$. Vadose Zone Journal, 2007; 6: 759-765.

[49] Evett S R, Tolk J A, Howell T A. Soil profile water content determination: Sensor accuracy, axial response, calibration, temperature dependence, and precision. Vadose Zone Journal, 2006; 5(3): 894-907.

[50] Olmanson O K, Ochsner T E. Comparing ambient temperature effects on heat pulse and time domain reflectometry soil water content measurements. Vadose Zone Journal, 2006; 5(2): 751-756.
[51] Palaparthy V S, Baghini M S, Singh D N. Compensation of temperature effects for in-situ soil moisture measurement by DPHP sensors. Computers and Electronics in Agriculture, 2017; 141: 73-80.

[52] Robinson D A, Campbell C S, Hopmans J W, et al. Soil moisture measurement for ecological and hydrological watershed-scale observatories: A review. Vadose Zone Journal, 2008; 7(1): 358-389.

[53] Palaparthy V S, Baghini M S, Singh D N. Review of polymer-based sensors for agriculture-related applications. Emerging Materials Research, 2013; 2(4): 166-180.

[54] Heitman J, Basinger J M, Kluitenberg G J, Ham J M, Frank J M, Barnes P L. Field evaluation of the dual-probe heat-pulse method for measuring soil water content. Vadose Zone Journal, 2003; 2(4): 552-560.

[55] Oates M J, Fernández-López A, Ferrández-Villena M, Ruiz-Canales A. Temperature compensation in a low cost frequency domain (capacitance based) soil moisture sensor. Agricultural Water Management, 2017; 183: 86-93.

[56] Kapilaratne R G C J, Lu M J. Automated general temperature correction method for dielectric soil moisture sensors. Journal of Hydrology, 2017; 551: 203-216.

[57] Palaparthy V S, Singh D N, Baghini M S. Compensation of temperature effects for in-situ soil moisture measurement by DPHP sensors. Computers and Electronics in Agriculture, 2017; 141: 73-80.

[58] Fares A, Safeeq M, Awal R, Fares S, Dogan A. Temperature and probe-to-probe variability effects on the performance of capacitance soil moisture sensors in an Oxisol. Vadose Zone Journal, 2016; 15(3): vzj2015.07.0098. doi: 10.2136/vzj2015.07.0098.

[59] Zheng R, Li Z, Gong Y. A coated helical transmission line time domain transmission sensor for measuring water content in saline soils. Soil Science Society of America Journal, 2011; 75(2): 397-407.

[60] Inoue M, Ahmed O, Saito T, Irshad M A, Uzoma K C. Comparison of three dielectric moisture sensors for measurement of water in saline sandy soil. Soil Use Management, 2008; 24(2): 156-162.

[61] Saito, T, Fujimaki, H, Inoue, M. Calibration and simultaneous monitoring of soil water content and salinity with capacitance and four-electrode probes. American Journal of Environmental Sciences, 2008; 4(6): 683-692.

[62] Bogena H R, Huisman J A, Oberdörster C, Vereecken H. Evaluation of a low-cost soil water content sensor for wireless network applications. Journal of Hydrology, 2007; 344(1-2): 32-42.

[63] Dias P C, Cadavid D, Ortega S, Ruiz A, França M B M, Morais F J O, et al Autonomous soil moisture sensor based on nanostructured thermosensitive resistors powered by an integrated thermoelectric generator. Sensors and Actuators A: Physical, 2016; 239: 1-7.

[64] Kojima Y, Shigeta R, Miyamoto N, Shirahama Y, Nishioka K, Mizoguchi $\mathrm{M}$, et al. Low-cost soil moisture profile probe using thin-film capacitors and a capacitive touch sensor. Sensors, 2016; 16(8): 1292. doi: 10.3390/ s16081292.

[65] Xu Z, Zhou W, Zhang H, et al. Flat thin mm-sized soil moisture sensor (MSMS) fabricated by gold compact discs etching for real-time in situ profiling. Sensors and Actuators B: Chemical, 2018; 255: 1166-1172.

[66] Goswami M P, Montazer B, Sarma U. Design and characterization of a fringing field capacitive soil moisture sensor. IEEE Transactions on Instrumentation and Measurement, 2018; 68(3): 913-922.

[67] Kalita H, Palaparthy V S, Baghini M S, Aslam M. Graphene quantum dot soil moisture sensor. Sensors and Actuators B: Chemical, 2016; 233 : 582-590.

[68] Xu K, Sheng Q, Zhang X, et al. Design and calibration of the unilateral sensitive soil moisture sensor. IEEE Sens Journal, 2015; 15(8): 4587-4594.

[69] Spelman D, Kinzli K D, Kunberger T. Calibration of the 10HS soil moisture sensor for southwest Florida agricultural soils. Journal of Irrigation and Drainage Engineering, 2013; 139(12): 965-971.

[70] Mittelbach H, Lehner I, Seneviratne S I. Comparison of four soil moisture sensor types under field conditions in Switzerland. Journal of Hydrology, 2012; 430-431: 39-49.

[71] Kargas G, Soulis K X. Performance analysis and calibration of a new low-cost capacitance soil moisture sensor. Journal of Irrigation and Drainage Engineering, 2012; 138(7): 632-641.

[72] Adeyemi O, Norton T, Grove I, Peets S. Performance evaluation of three newly developed soil moisture sensors. In: Proceedings of the CIGR-AgEng Conference, Aarhus, Denmark, 2016; pp.26-29.

[73] Datta S, Taghvaeian S, Ochsner T, Moriasi D, Gowda P, Steiner J. Performance assessment of five different soil moisture sensors under irrigated field conditions in Oklahoma. Sensors, 2018; 18(11): 3786. 
doi: $10.3390 / \mathrm{s} 18113786$.

[74] Muzdrikah F S, Nuha M S, Rizqi F A. Calibration of capacitive soil moisture sensor (SKU: SEN0193). In: 4th International Conference on Science and Technology (ICST), IEEE, 2018; pp.1-6.

[75] Placidi P, Gasperini L, Grassi A, Cecconi M, Scorzoni A. Characterization of low-cost capacitive soil moisture sensors for IoT networks. Sensors, 2020; 20(12): 3585. doi: 10.3390/s20123585.

[76] Nagahage E A A D, Nagahage I S P, Fujino T. Calibration and validation of a low-cost capacitive moisture sensor to integrate the automated soil moisture monitoring system. Agriculture, 2019; 9(7): 141. doi: 10.3390/agriculture9070141.

[77] Saeed I A, Wang M J, Ren Y R, Shi Q L, Malik M H, Tao S, et al. Performance analysis of dielectric soil moisture sensor. Soil and Water Research, 2019; 14(4): 195-199.

[78] Saeed I A, Shi Q L, Wang M J, Butt S L, Zheng L H, Tuan V N, et al. Development of a low-cost multi-depth real-time soil moisture sensor using time division multiplexing approach. IEEE Access, 2019; 7: 19688-19697.

[79] González-Teruel J D, Torres-Sánchez R, Blaya-Ros P J, Toledo-Moreo A B, Jiménez-Buendia M, Soto-Vallas F. Design and calibration of a low-cost SDI-12 soil moisture sensor. Sensors, 2019; 19(3): 491. doi: 10.3390/ s19030491.

[80] Kumar M S, Chandra T R, Kumar D P, Manikandan M S. Monitoring moisture of soil using low cost homemade soil moisture sensor and Arduino UNO. In: 2016 3rd International Conference on Advanced Computing and Communication Systems (ICACCS), IEEE, 2016; pp.1-4. doi: 10.1109/ICACCS.2016.7586312

[81] Shamshiri R R, Hameed I A, Thorp K R, Balasundram S K, Shafian S, Fatemieh $\mathrm{M}$, et al. Greenhouse automation using wireless sensors and IoT instruments integrated with artificial intelligence. In: Next-generation greenhouses for food security, 2021. doi: 10.5772/intechopen.97714.

[82] Varble J L, Chávez J L. Performance evaluation and calibration of soil water content and potential sensors for agricultural soils in eastern Colorado. Agricultural Water Management, 2011; 101(1): 93-106.

[83] Bell J P, Dean T J, Hodnett M G. Soil moisture measurement by an improved capacitance technique, part II. Field techniques, evaluation and calibration. Journal of Hydrology, 1987; 93: 79-90.

[84] Tomer M D, Anderson J L. Field evaluation of a soil water-capacitance probe in a field sand. Soil Science, 1995; 159: 90-98.

[85] Nadler A, Lapid Y. An improved capacitance sensor for in situ monitoring of soil moisture. Australian Journal of Soil Research, 1996; 34(3): 361-368.

[86] Torres-Sanchez R, Navarro-Hellin H, Guillamon-Frutos A, et al. A decision support system for irrigation management: Analysis and implementation of different learning techniques. Water, 2020; 12(2): 548 doi: 10.3390/w12020548

[87] Coelho E F, Or D. Flow and uptake patterns affecting soil water sensor placement for drip irrigation management. Transactions of the ASAE, 1996; 39(6): 2007-2016.

[88] Aljoumani B, Sànchez-Espigares J A, Canameras N, Josa R, Monserrat J Time series outlier and intervention analysis: Irrigation management influences on soil water content in silty loam soil. Agricultural Water Management, 2012; 111: 105-114.

[89] Gao Z, Zhu Y, Liu C, Qian H Z, Cao W X, Ni J. Design and test of a soil profile moisture sensor based on sensitive soil layers. Sensors, 2018; 18(5): 1648. doi: 10.3390/s18051648.

[90] Soulis K X, Elmaloglou S, Dercas N. Investigating the effects of soil moisture sensors positioning and accuracy on soil moisture based drip irrigation scheduling systems. Agricultural Water Management, 2015; 148 258-268.

[91] Wild J, Kopecký M, Macek M, Sanda M, Jankovec J, Haase T. Climate at ecologically relevant scales: A new temperature and soil moisture logger for long-term microclimate measurement. Agricultural and Forest Meteorology, 2019; 268: 40-47.

[92] Athani S, Tejeshwar C H, Patil M M, Patil P, Kulkarni R. Soil moisture monitoring using IoT enabled arduino sensors with neural networks for improving soil management for farmers and predict seasonal rainfall for planning future harvest in North Karnataka-India. In: 2017 International Conference on I-SMAC (IoT in Social, Mobile, Analytics and Cloud) (I-SMAC), IEEE, 2017; pp.43-48. doi: 10.1109/I-SMAC.2017.8058385. 